\title{
Evaluation of the Range Condition Concept
}

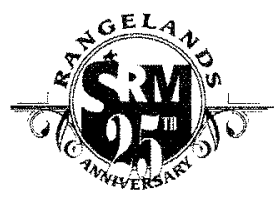

\author{
If the term "range condition" can be retained, it should refer to site \\ condition, not the use rating, since site condition is closer to the \\ concept of "the state of range health."
}

\author{
By E. Lamar Smith
}

As a tribute to the $25^{\text {th }}$ anniversary of Rangelands, we present this article which first appeared in "Rangelands" in April 1979.

(April 2003) When asked to reflect on the subject of this paper, my first thought was that we have come a long way since 1978-79. The climax approach to range condition assessment and the successional model on which it was based are no longer accepted (at least not openly) as universal by most range ecologists, and the ecological site concept has gained scientific acceptance. Changes in concepts and terminology have been proposed and some of them implemented.Now range professionals speak of "multiple pathways", "states and transitions", "resource value ratings", "seral stages", "desired plant communities", "thresholds" of various sorts, and "rangeland health." But the concept of pristine ecosystems existing in an intricately co-evolved state of balance and perfection that can be easily upset, i.e. degraded, by man-caused "disturbance" persists in most of the natural resource professions and among environmental activists. Publications and management objectives are full of references to "natural" processes and conditions, implying that use and management of resources should aim to restore such conditions or at least not detectably "degrade" them. The concept of setting objectives based on human needs and managing for them in a sustainable way seems to have lost ground to "protection" of nature for nature's sake. "Rangeland health" (an old term associated with range condition, which I regrettably used to end my paper), as it is being applied, all too often seems to be a reincarnation of the value-laden terminology and "organismic" concept of ecosystems that characterized the climax approach to range condition. Maybe we haven't come very far after all.

Editor's Note (Danny Freeman) in 1979: This article provides a good discussion about range condition ratings. Hopefully, it will encourage agencies and others to use range condition terminology that means the same thing to everybody.
The concept of range condition (and trend) is perhaps the most important one in range management. The idea that the present status of rangeland in relation to its potential could be evaluated and used to indicate effectiveness of management and potential for improvement goes back to about the turn of the century. While the concept has been widely accepted, used, and discussed, it is apparent that considerable confusion still exists relative to exactly what is being measured and why. This article examines the reasons for some of this confusion and suggests changes to reduce this confusion.

Classification of range sites is fundamental to the concept of range condition. Obviously, if condition is to be rated relative to potential, the potential must be defined. Range sites (or roughly equivalent terms, such as habitat type or land units) have been characterized somewhat differently by various individuals or agencies. However, the main concept is of a kind of land which has potential to produce a certain kind or amount of vegetation, which has certain other intrinsic characteristics, such as susceptibility to erosion, and which responds to management in a distinctive way. The primary factors distinguishing one site from another are soil, topography, and climate; thus range sites can be recognized irrespective of present use or vegetative cover.

Hacker (1973) pointed out that there are two basic approaches to rating range condition on a site. One he referred to as ecologically based and the other as productivity based. In the first, condition is rated relative to the observed or inferred climax or pristine vegetation for the site. This rating usually involves comparison of present vegetation (and sometimes soil characteristics) with reference areas presumed to exhibit climax or near-climax conditions. "Ecological condition" is not affected by the intended use of the range. The assumption is usually made that climax vegetation will provide adequate soil protection. In the United States, the "climax" approach proposed by Dyksterhuis 
Areas shown in these three photos all represent loamy upland range sites at the Santa Rita Experimental Range. All three have similar soils and rainfall.

This study plot has been excluded from grazing since 1916. The vegetation does not represent "original" conditions because brush and cactus have increased. Present range condition rates only fair by SCS standards because, even though the grasses are mostly "climax" species, brush and cactus are mostly considered invaders on the site. Yet, there is little to suggest that condition will improve without man's intervention. Soil protection and site stability are obviously not too good because of the amount of bare soil and sheet erosion. Forage production for livestock is low but habitat for deer, javelina and quail is relatively good.

This area has been invaded by mesquite, other shrubs and also Lehmann's lovegrass, an exotic species, which makes up about half of the perennial grass composition. Since both mesquite and Lehmann's lovegrass are considered invaders by the SCS, this site also rates low fair to poor in range condition. However, forage production for livestock is higher than in Photo 1 and there is little or no evidence of erosion.

This exclosure was also fenced in about 1916. Invasion of mesquite has been minimal, but Lehmann's lovegrass, which was introduced on the Santa Rita 20 years after the exclosure was fenced, has spread naturally into the area both inside and outside the exclosure. It now composes about $90 \%$ of the plant composition outside the exclosure and about $70 \%$ inside. Range condition based on "climax" is low fair to poor inside and very poor outside, yet forage production for livestock is much better than on either of the locations above. Soil protection is excellent. Habitat for most game animals is inferior to the other two locations.
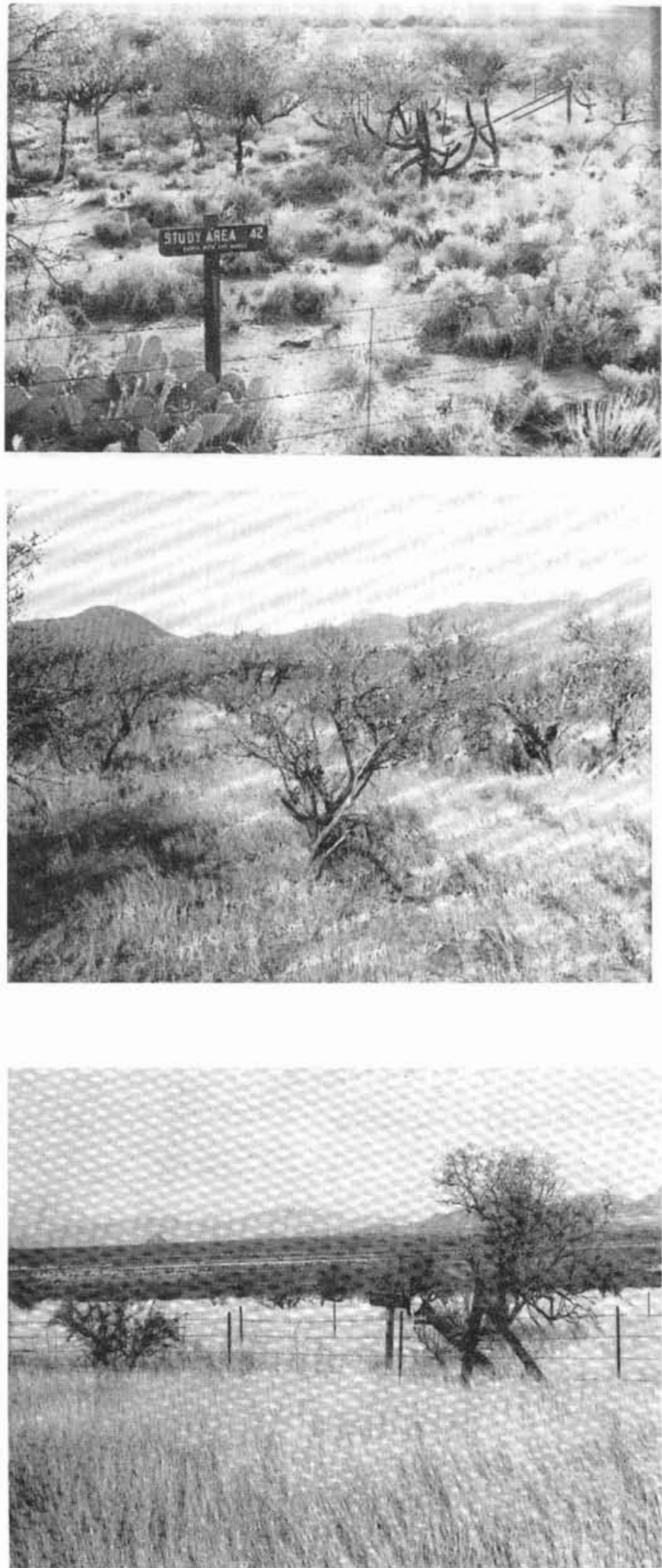
(1949) and presently used by the Soil Conservation Service and others is an example of this approach.

The productivity-based approach rates range condition according to present productivity in relation to the potential for a particular use. In this approach, every actual or proposed use of the site has a different condition rating. For example, a site producing near its potential in terms of forage for cattle would be rated excellent for cattle grazing, but might be considered only fair for grazing of sheep or deer. Condition ratings do not imply site stability since condition may vary from poor to excellent on the same site, depending on the use considered. This approach has been generally referred to as the "site-potential" approach in the United States (Humphrey 1949).

In practice these two approaches have often been confused. For example, the Soil Conservation Service has claimed to use the climax approach. But, in fact, for many years their classification of the status of plant species in relation to climax vegetation (the decreaser, increaser, invader concept of Dyksterhuis, 1949) was definitely biased toward livestock use, especially cattle. On most range sites almost all perennial grasses were considered climax species (decreasers or increasers) and almost all unpalatable shrubs were considered invaders. Recently, in response to pressure for other uses and as a result of ecological research, the Soil Conservation Service has come closer to the strictly ecological approach. Although the Forest Service has never adequately recognized site differences and, consequently, has confused site potential with range condition, it too has followed the same general pattern as the Soil Conservation Service. As a result, it is now common for range managers to distinguish between "ecological condition" and condition for specific uses such as cattle grazing, watershed protection, or wildlife habitat. In my opinion this is a step in the right direction.

Strict adherence to the climax approach creates some problems in the concept of range condition. First is the problem of recognition that condition based on climax is not always meaningful in management terms. It is generally recognized that the climax or near-climax condition is not necessarily best for a given use. Thus, a manager's objective may be to manage the range to maintain "good" or "fair" condition rather than "excellent." This may be biologically sound, but it is undesirable from a management standpoint. The utility of condition ratings in pointing out to the manager where management needs to be improved is reduced, since a condition of "fair" may be desirable on one site but indicate a need for improved management on another. Also, in these days of public scrutiny of resource management, deliberately managing for "fair" condition rather than "excellent" may have serious consequences for range users. The layman may assume that any rating below "excellent" indicates poor stewardship of the land. Psychologically, it would be better to aim for excellence. Perhaps this problem could be at least partially solved by dropping the descriptive terms and using a numerical rating.

A second problem is related to the difficulty of defining what is the "climax" for any given site. It has been well documented in the American Southwest that much rangeland which was formerly grassland has been invaded by mesquite, juniper, creosote bush, small pines, and other woody species since about 1900. The causes of this invasion have been laid to climatic change, exclusion of fire, and/or overgrazing. Whatever the reason, the plant communities have changed and there is little evidence that natural succession will bring them back to their pristine state unless the environmental conditions of that pristine state (i.e., burning, climatic patterns) are also restored. Should range condition be measured relative to that pristine grassland or to the new climax dominated by woody plants?

A third problem is that the ecological concept, as used in the United States, does not accommodate exotic species because they are not considered part of the climax vegetation. Therefore, most seeded stands cannot be rated as to range condition since most of them are composed of exotic species. Similarly, the presence of alien species in native plant communities may lower the condition rating even though they are naturalized and contribute materially to forage production or other values.

A fourth difficulty is related to the problem of rating condition as a departure from climax where the cli$\max$ is forest or woodland rather than grassland or shrubland. Forage production may decline to a very low level as the forest or woodland climax is approached. In a sense this situation is not different from the admission that "excellent" condition ecologically is not necessarily "excellent" from the range forage standpoint. In this case it is so contrary to our usual concept of range condition that the Soil Conservation Service has abandoned the ecologically based rating of range condition of "grazeable woodlands" or forest clearings in favor of a rating of forage quantity and quality, a site potential approach. (This approach is outlined in its 1976 National Range Handbook.) Such areas are not even considered rangeland. It is not clear why the addition of a tree overstory should result in a 
complete change in the approach to condition or just where or why the line between rangeland, grazeable woodland or forest should be drawn. The basic purpose of range condition and trend assessment is to evaluate the effects of management on site stability and habitat desirability. Fulfilling this purpose seems as important on grazed forest or woodland as on grassland or shrubland.

The most basic concept in management of renewable natural resources is that of sustained yield, which implies that potential site productivity will not be impaired by man's actions. There may be a wide range of possible uses for a site, but degradation of the site will reduce the number and/or value of the uses possible, thus reducing future options for management. Any measurement of range condition, then, must at least establish whether the site is deteriorating or not as a result of past and current management. Site deterioration would be most likely reflected in accelerated soil erosion.

The assumption implicit in ecologically based range condition is that the climax vegetation will provide site stability. But, if it is assumed that we can manage for something less than climax, e.g., "fair" condition, then we are also assuming either that climax vegetation is not a necessary condition for site stability or that a measure of stability can be sacrificed. However, it is not evident whether site deterioration begins with poor condition, fair, good, or even the slightest departure from climax. The degree of departure from cli$\max$ at which site deterioration becomes significant may vary from one site to another. In other words, on one site soil stability may decline with a slight departure from climax while on another the soil may remain stable even if all of the vegetation is removed. Therefore, a rating of site condition is needed which would be primarily based on soil characteristics and independent of the type, amount, or successional status of the plant species on it. This rating would simply indicate if site condition is satisfactory or unsatisfactory relative to the potential stability for the site. A rating of unsatisfactory would indicate that management must be changed to bring the site back to a relatively stable condition. If site condition is satisfactory and trend is not down, then present management is adequate from a site protection standpoint.

If site condition and trend are satisfactory (i.e., the site is not deteriorating) the decision as to whether the present characteristics of the vegetation are desirable or undesirable depends on the planned use of the site. "Condition" in this case would follow the site-potential approach in that the present utility of vegetation for each use would be judged a high, medium, or low in relation to the best possible condition for that par- ticular use on that site. The characteristics of the site, including climate, determine the potential for a particular use including the possibility of modification of the site by irrigation, fertilization, introduction of new species, etc. The goal of management would be determined by the capability of the site for various uses and the mix of uses which would give the highest return economically, esthetically, etc. The need for changes in management strategy would be determined by how nearly the present situation approaches the potential for the uses desired, both individually and collectively. For example, if the decision was to maximize livestock forage then the goal would be to achieve high condition, i.e., near the site potential, for that purpose. However, if the management goal is to maximize timber production, then the forage condition expected is low to medium. In this case "low" does not represent an undesirable condition but a rational management decision.

To summarize, I propose that the concept of range condition as it is generally used is inadequate and should be modified. Each range site has a number of possible uses and potential values for each use. Management should not permanently reduce the number of possible uses or the potential value of each. A measure of site condition, based primarily on soil characteristics, should be developed to indicate the success of management in maintaining the site and should indicate whether present condition is satisfactory or unsatisfactory. A rating should also be made for each possible use of interest to the manager as to how nearly the present vegetation approximates the most useful type of potential vegetative cover for that particular use. This rating could be expressed simply as a percentage or as a descriptive modifier such as high, medium, or low. If the term "range condition" can be retained without confusion it should refer to site condition, not the use rating, since site condition is closer to the concept of "the state of range health."

\section{References}

Dyksterhuis, E.J. 1949. Condition and management of rangeland based on quantitative ecology. J. Range Manage. 2:104-115.

Hacker, R.B. 1973. The objectives of land resource management. Arid Zone Newsletter, CSIRO, Perth, Australia. p. 112-119.

Humphrey, R.R.1949. Field comments on the range condition method of forage survey. J. Range Manage. 2:1-10.

The author is associate professor, School of Renewable Natural Resources, University of Arizona, Tucson. This article is based on a paper presented by the author at the First International Rangeland Congress, August 1978, in Denver, Colorado. 